students and teachers of pathology. It will also be a work of reference for those more interested in the direct effects of toxicants on the behaviour and metabolism of microorganisms. The amount and type of information ensure that the book will retain its value for many years to come.

R. K. S. WOOD

\section{FUNGAL GENETICS}

\section{Genetics of Fungi}

By Karl Esser and Rudolf Kuenen. 'Translated by Erich Steiner. Pp. $\mathrm{x}+500$. (Berlin and New York: SpringerVerlag, 1967.) $74 \mathrm{DM}$; $\$ 18.50$.

Thrs book, originally published in German in 1965, has now been competently translated for the benefit of the English reader. Though they have not carried out an extensive revision, the authors have interpolated into the English edition a number of reforonces to recent work and have substantially enlarged their bibliography to include papers published as recently as 1967 .

The book starts with an outline of the morphology of the main fungal groups with emphasis on forms important in genetic research. Thereafter, there are two short chapters, on replication (largely a summary of the facts about DNA derived from bacterial work) and on extrachromosomal inheritance, and four long ones on reproduction, recombination, mutation and function. It is these four long chapters which constitute the real meat of the book.

The chapter on reproduction gives a thorough description and discussion of the great diversity of breeding systoms occurring in fungi. Questions of terminology are prominent; perhaps too much so. The authors eschew the terms homothallic and heterothallic and prefer the eategories monoecious and dioecious. Thus Neurospora is monoccious and self-incompatible, but Saccharomyces, because it does not have differentiated male and female sex organs, does not qualify as monoecious nor, apparently, as self-incompatible and has to be termed physiologically dioecious. All this is rather difficult for those brought up with a different system and I cannot feel that it advances our understanding of what fungi actually do. In the chapter on recombination we find a detailed account of data and theories on intragenic recombination, but the most emphasis is given to intergenic crossing-over, especially as studied by tetrad analysis. The chapter on function is particularly strong on biosynthetic pathways, and the concise and complete summaries given in the tables and figures will be very useful for reference purposes.

In general the authors have tried, with considerable success, to do justico to all contributors to the field of fungal genetics, but to somo extent comprehensiveness has been achieved at the expense of clarity. The bibliography is a very full one, and not all the papers cited are discussed individually, some being referred to so briefly that the reader is given little more than a hint of the nature of their conclusions. Substantial sections of the text which deal with matters of detail are printed in small type, but even with this degree of typographical compression the authors have not given themselves enough space to make all their points as clearly as one would wish. There are also a number of factual inaccuracies, some of which seem worth mentioning. Heterokaryon compatibility in Neurospora crassa certainly is controlled by the mating type alloles, among other factors, contrary to what is suggested on page 98. The statement (page 215) that Manney and Mortimer's method for genetic mapping by $\mathrm{X}$-rays in yeast depends on mutation (rathor than recombination) is misleading. To imply (page 227) that polarized conversion is known only in Ascobolus and is not found in Neurospora is confusing, especially when followed by the statement that polarized recombina- tion does occur in Neurospora (the possible connexion is not made clear). It is doubtful, to say the least, whether there is any genetic evidence for induced diploidy in Neurospora (page 317 ). On page 228 , X-ray sensitivity in yeast is said to increase with increasing ploidy, which seems to be the wrong way round. In a book as packed with information as this one, however, some slips must be expected, and at least the true facts far outnumber the wrong ones.

The book is very well produced and illustrated. It will be of value to any specialist in fungal genetics.

J. R. S. FINCHAM

\section{INVERTS WITHOUT ENTHUSIASM}

\section{The Free-Living Lower Invertebrates}

By Frederick M. Bayer and Harding B. Owre. Pp. viii + 229. (New York: The Macmillan Company; London: Collier-Macmillan, 1968.) 112s.

THE declared aim of Bayer and Owre's book, The Firee. Living Lower Invertebrates, is "to bridge the gap between textbook and treatise with a volume of moderate complexity". They include five phyla among the lower invertebrates, Porifera, Coelenterata, Ctenophora, Platyhelminthes and Nemertea. Apparently the Protozoa play in a different league.

It is difficult to make a review of this book very interesting because it is not a very interesting book. For each phylum there is a brief introduction, a description of morphology and classification, a short account of reproduction and usually a few paragraphs on physiology, ecology and distribution. The limitations imposed by this uniform treatment do not make for excitement, and if the authors felt any when confronted by the panorama of invertebrate life, they manage to conceal it. Nor has the uniform treatment the virtues of being comprehensive and easily referred to, because the only typographical variation which is permitted is the occasional name or term in italies. Only nine titles are quoted in the half page bibliography and seven of these are well known books. Any modern work which deals with a limited part of the animal kingdom at degree level should surely scok to integrate classical morphology with modern microscopic anatomy and with physiology and ecology.

Ten pages of the text are devoted to listing the sources of the illustrations, more than one half of which are from works published more than 50 years ago. This is not meant to imply that they are bad but that most of them have been used so frequently for the illustration of textbooks that they are familiar faces even when redrawn in the very competent and meticulous, but rather lifeless, style of the illustrator. Of course, after Hyman, it is difficult to get good illustrations that have not been used before, but one should not forget that The Invertebrates, Vol. 1, was published more than a quarter of a century ago and quite a lot of work has been done on invertebrates since then.

Garth Chapman

\section{BIOENERGETICS AND METABOLISM}

\section{Metabolic Pathways}

Vol. 1: Energetics, Tricarboxylic Acid Cycle, and Carbo. hydrates. Third edition. Edited by David M. Greenberg. Pp. xiii +460 . 210s. Vol. 2: Lipids, Steroids, and Carotenoids. Third edition. Edited by David M. Greenberg. Pp. xiii +311 . 130s. (New York: Academic Press, Inc.; London: Academic Press, Inc. (London), Ltd, 1967-68.)

The third edition of Metabolic Pathways has been planned in four volumes, and the first two, now published, cover bioenergetics and the metabolism of carbohydrates, lipids. steroids and carotenoids. It is planned to cover nitrogen 